lessening of cardiac chamber size, wall tension, and oxygen consumption. After-load reduction, with a drop in impedance enabling ejection against less resistance, also lowers myocardial oxygen consumption. The duration of action is approximately four hours and the frequency of dosage should thus be at least every four hours. An effective dose should cause a reduction in systolic blood pressure an hour after ingestion. The starting dose is usually $10 \mathrm{mg}$ five to six times daily and may be increased to as much as 40 to $50 \mathrm{mg}$ at the same frequency. Some patients will initially have a headache which responds well to mild analgesics. This is usually not a persistent problem and in many patients the headache disappears or diminishes considerably despite continuing the drug.

We use sorbide nitrate frequently. In three of our patients with classic angina pectoris we conducted a double-blind, ergometric exercise-tolerance study and found that in all there was a two to threefold increase in their work capacity after taking 10 or $20 \mathrm{mg}$ of sorbide nitrate as compared to placebo. This improvement peaked at one hour and returned to control levels by four hours. The $20 \mathrm{mg}$ dose was significantly superior to the $10 \mathrm{mg}$ dose.

We should like to call the attention of those interested in this problem to an excellent recent review article ${ }^{4}$ that concludes that despite past controversy the usefulness of long-acting nitrates in high dosage in angina pectoris is well established.

D WEILER-RAVELL M M BASSAN

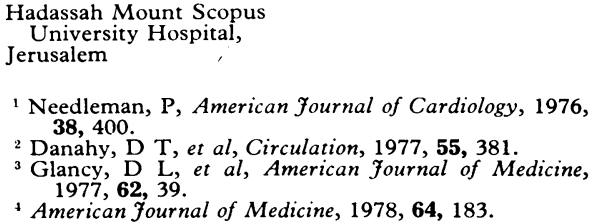

\section{Drugs and breast-feeding}

SIR,-We read with interest your leading article on the problems of drugs and breast feeding and the uncertainty that surrounds much of our knowledge on this subject (10 March, p 642). May we therefore present some information pertinent to a widely prescribed product.

At Dudley Road Hospital we are investigating the use of metronidazole rectal suppositories ( $1 \mathrm{~g}$ eight hourly, seven doses) in the prevention of .infection following caesarean section, and breast milk samples collected within 30 minutes of completing this treatment have been analysed. The initial results (eight patients) are as follows: mean metronidazole concentration in milk: $10 \mu \mathrm{g} / \mathrm{ml}(10 \mathrm{mg} / \mathrm{l})$; maximum metronidazole concentration in milk: $25 \mu \mathrm{g} / \mathrm{ml}(25 \mathrm{mg} / \mathrm{l})$.

Following the work of Khan and Nixon ${ }^{1}$ the recommended paediatric dosage of metronidazole is $7.5 \mathrm{mg} / \mathrm{kg} / 8 \mathrm{~h}$ (Data Sheet Compendium), which represents $15 \mathrm{mg} / 4 \mathrm{~h}$ for a $4 \mathrm{~kg}$ infant. Calculating from the average posttreatment metronidazole concentration in our study, it would require a breast milk intake of $1500 \mathrm{ml} / 4 \mathrm{~h}$ or, calculating from the maximum post-treatment metronidazole concentration, an intake of $600 \mathrm{ml} / 4 \mathrm{~h}$, to achieve this dosage.

Our initial results suggest therefore that the prophylactic use of metronidazole suppositories at the dosage stipulated is unlikely to have any harmful effect on the breast-fed neonate. The situation, however, may be different for the older breast-fed child taking larger quantities of milk from a mother receiving metronidazole.

Dudley Road Hospital,
Birmingham B18 7QH

B MOORE

JOHN COLLIER

May and Baker Limited Dagenham, Essex

${ }^{1}$ Khan, $\mathrm{O}$, and Nixon, $\mathrm{H} \mathrm{H}$, Kinderchirurgie, 1978, 25,

\section{Cetiprin and oesophageal ulceration}

SIR,-Mr F J Collins and others draw attention to a case of oesophageal ulceration following the ingestion of a tablet of emepronium bromide $200 \mathrm{mg}$ (23 June, p 1673).

The fact that the patient "swallowed the tablet dry, as was her normal practice," demonstrates that the treatment was not prescribed according to the manufacturer's instructions-namely, that the tablet should be swallowed with an adequate amount of fluid.

All tablets nowadays are formulated to disintegrate rapidly in contact with water. This is achieved by incorporating swelling agents that need a small amount of water to exhibit their effect. When a tablet is swallowed with too little fluid the hygroscopicity of the tablet can cause it to stick to the oesophageal mucosa, resulting in local irritation and ulceration. Patients who have difficulty in swallowing Cetiprin tablets should take them as a slurry in water.

Allan D Lauder

Kabivitrum Ltd,

London W5 2TH

Tory health

SIR,-Your leading article, "Tory health" (9 June, p 1522), discusses "joint responsibility of the Government and the medical profession to see that people know the basic facts about health," but points out the difficulties of spreading health education. Surely there is more scope for medical education through the mass media, particularly television. Medical programmes on television tend to highlight new and sensational developments. The information may be of great interest but will provide little direct benefit except perhaps for members of the medical profession. A recent programme on normal and abnormal sexual differentiation, for example, was fascinating but hardly likely to save lives, or significantly affect the health of the country.

Public education could be of particular value in preventing deaths from coronary artery disease, not only by reducing risk factors such as smoking but also by ensuring that patients with myocardial infarction reach medical care as promptly as possible. The following case illustrates the potential value of medical advice provided through television.

A 42-year-old man developed typical symptoms of myocardial infarction on 13 April, the day after watching a television programme about heart attacks. Not only did he correctly interpret his symptoms but he also arranged for a relative to take him directly to the nearest accident and emergency department. He developed ventricular fibrillation within a few minutes of being admitted. Immediate electrical defibrillation was successful and he lived to tell the story. $\mathrm{He}$ is emphatic that had he not watched the programme he would have attributed his symptoms to indigestion and called his general practitioner. He pointed out that 13 April was Good Friday.

Television already provides education on the prevention of accidents. Is it not time that this role was extended? Perhaps there is a joint responsibility of the broadcasting authorities and the medical profession to see that people know the basic facts about health.

\section{R H LLOYD-MOSTYN}

King's Mill Hospital,

Sutton-in-Ashfield, Notts NG17 4JL

\section{Sodium in peritoneal dialysis solutions}

SIR,-We agree with the conclusion reached in the paper by $\operatorname{Dr}$ P G Bisson and $\mathrm{Mr} \mathrm{K} \mathrm{M}$ Bailey on sodium in peritoneal dialysis solutions (19 May, p 1322). Similar standards should be applied to solutions for peritoneal dialysis and haemodialysis.

We do not, however, agree with the routine use of high-sodium dialysate $(141 \mathrm{mmol} / \mathrm{l})$ for chronic dialysis. Resultant high or high-normal postdialysis plasma sodium concentrations potentially contribute to both hypertension and excess thirst. Routinely using the lowsodium dialysate $(130 \mathrm{mmol} / \mathrm{l})$ we have not witnessed the hypernatraemia-related postdialysis problems described. Neither have we noted any significant hyponatraemia. It is even possible that a sodium of $130 \mathrm{mmol} / \mathrm{l}$ is too high as we are aware of one large peritoneal dialysis programme which routinely and successfully uses dialysate with a sodium concentration of $120 \mathrm{mmol} / \mathrm{l}$ (C Comty, personal communication, 1978).

A $M$ W FORBES H J GOLDSMITH

Sefton General Hospital Liverpool L15 $2 \mathrm{HE}$

\section{Legal ignorance}

SIR,-We are respectively a medically qualified clinical tutor in child health and a solicitor with a close involvement in the problem of child protection and medical law. The work of each of us means that we have to acquire some knowledge of the skills of our sister profession, and we are continually dismayed by the ignorance demonstrated by practitioners of certain fundamental facts and procedures that each profession should know. In our case this has become manifest in the field of child care, but we have reason to think that it exists at every level.

As an example of what we mean we quote some answers given by 101 medical students when asked the meaning of a "place of safety order." Ten thought that it prevents those over 14 years using playgrounds in public places. Eight thought it insists that playgrounds in all primary schools should be completely fenced in. Six thought that it compelled a parent to take a child for regular medical inspection. Five thought it was an order forbidding children under 12 years to handle fireworks except in a private garden. Twenty-three thought it was granted where a family of small children were homeless. Nine thought the order lasted for six months. Two thought the order had to be signed by the Chief Constable or his assistant. Eleven 